\title{
Analysis of the Social and Economic Factors of Wastewater Discharge in China
}

\author{
Fang Wang ${ }^{1,2}$, Hsing Hung Chen ${ }^{1, *}$ \\ ${ }^{1}$ School of Business, Macau University of Science and Technology \\ ${ }^{2}$ Audit Office, Yancheng Teachers University \\ *Corresponding author. Email: hhchen@must.edu.mo
}

\begin{abstract}
In many developing countries, especially in China, water pollution, which brings a great threat to public health, is a serious problem. In order to control water pollution and provide the scientific basis for governments to make the sustainable development plan, it is very important to find out the social and economic factors of wastewater discharge. In this paper, six social and economic factors affecting wastewater discharge are selected and analyzed. These six factors are GDP, per capita GDP, R \& D investment, foreign direct investment, industrial structure and environmental awareness. Governments at all levels can adjust these six factors to achieve the goal of protecting the ecological environment while developing the economy.
\end{abstract}

Keywords: Wastewater discharge, Socioeconomic determinants, Sustainability, China

\section{INTRODUCTION}

The rapid economic growth has posed a challenge to sustainable development in the developing countries, especially in China. In China, water pollution is a serious problem. Waste water is a kind of important source of environmental pollutants, which can be transferred to the rest of the world through runoff naturally and water pollution can be indirectly shifted to other countries by certain economic activities[1]. In addition, the wastewater pollutes directly the local groundwater and soil, and ultimately affects food safety and people's health[2]. The water quality is affected by both wastewater discharge and self-purification[3]. Assuming that the self-purification capacity of water body in a certain area is fixed, the water quality is mainly influenced by the total amount of wastewater discharge in a certain period. However, the local social and economic development level and economic aggregate contribute to the quantity of wastewater discharge in an area. For the sustainable development of social and economy, the socio-economic factors affecting wastewater discharge should be coordinated in the formulation of economic and social development plans. Therefore, it is rather significant to find out the socioeconomic factors that affect the total amount of wastewater discharge in the future.
In order to explore the socio-economic causes of wastewater discharge in more detail, we need to determine the main socio-economic indicators which affect wastewater discharge. At present, there are many researches on the influencing factors of environmental pollution. For example, Sekeret al.[4] believed that the main influencing factors of carbon dioxide $\left(\mathrm{CO}_{2}\right)$ emissions are gross domestic product (GDP), the square of GDP, and energy consumption. Xu and Lin[5] discussed the driving forces of regional differences in $\mathrm{PM}_{2.5}$ pollution and identified economic growth, energy efficiency, urbanization, industrialization and energy structure as main forces. Liuet al.[6] analyzed the factors of haze pollution in Chinese cities and found that the factors influencing haze pollution included urbanization, population, GDP, added value of secondary industry, the amount of private cars, the total quantity of land used for urban construction. Wanget al.[7] studied the impact of socio-economic factors on $\mathrm{CO}_{2}$ emissions in cities experiencing rapid urbanization, and supposed that economic growth, industrialization and urbanization lead to a significant increase in carbon dioxide emissions, but service level and technical level reduce the carbon dioxide emissions. Coleet al.[8] pointed out that the decisive factor of $\mathrm{CO}_{2}$ emissions are the capital-labor ratio, the size of firms, the exports, R\&D spending and focus for public profile. 
Although scholars have paid much attention to the factors affecting environmental pollution, there are few reports on the socio-economic factors affecting the total amount of waste water emission. This is the main contribution of this paper.

\section{WASTEWATER DISCHARGE}

The wastewater in this article includes domestic sewage and industrial wastewater. The data were obtained from Statistical Yearbook of China. The larger the value is, the more the quantity of wastewater discharge is. Figure 1 is a time series chart of the total wastewater discharge in China from 1998 to 2017. It can be found from Figure 1 that from 1998 to 2017, the wastewater discharge increased year by year first, peaked at 73,473.43 million tons in 2015 , and then showed a slow downward trend. The reasons why wastewater discharge has been declining in recent years may be the development of society and economy in China. In 2017, the total wastewater discharge was still 69,894.35 million tons, indicating that China's wastewater pollution is still serious, and the environmental protection situation is still severe.

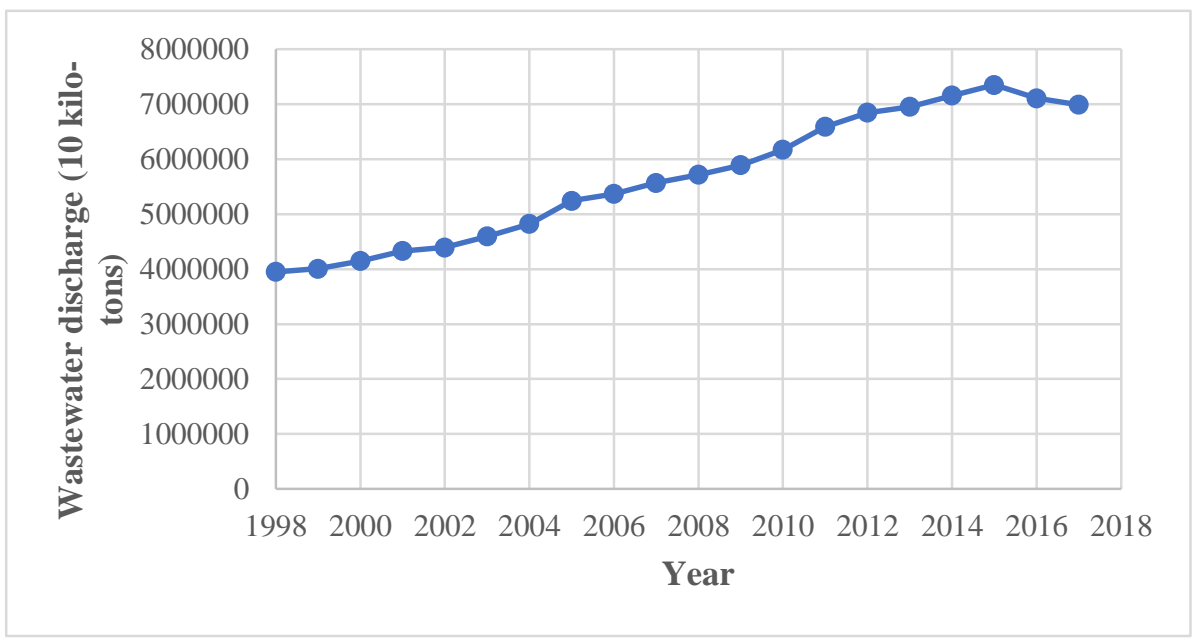

Figure 1 Wastewater discharge in China over 1998-2017.

In order to identify the spatial distribution of wastewater discharge in China, the spatial-temporal distribution map of wastewater discharge in each province was obtained by transforming the wastewater discharge amount of each province into the vector of GIS administrative unit (see Figure 2). Figure 2 indicates the spatial distribution of waste water emission in China for 2007 and 2017 respectively. We use different colors to represent different quantities of wastewater discharge. In terms of spatial distribution, wastewater discharge in China is high in the eastern and southern regions, and low in the western and northern regions. It can be seen from Figure 2 that Guangdong and Jiangsu province had the largest amounts of wastewater discharge in China, exceeding 3381.01 million tons and 8820.2 million tons in 2007 and 2017 respectively. The quantities of wastewater discharge in Gansu Province, Qinghai Province and Ningxia Hui Autonomous Region were all at a low level. The GDPs of Guangdong Province and Jiangsu Province are always in the forefront of the country, while the GDPs of Gansu Province, Qinghai Province and Ningxia Hui Autonomous Region are relatively small, which may be the main reason why the quantities of wastewater discharge of Guangdong Province and Jiangsu Province are large, and they are small in Qinghai Province, Gansu Province and Ningxia Hui Autonomous Region.



Figure 2 The discharge quantity of wastewater in each province in 2007 and 2017. 


\section{DETERMINANTS OF WASTEWATER DISCHARGE}

Inspired by previous studies, we analyzed the social and economic factors affecting wastewater discharge from six aspects. The data of GDP, GDP per capita, foreign direct investment, industrial structure, $R \& D$ investment and environmental awareness of 30 provinces are all from China Statistical Yearbook, China Science and technology statistical yearbook, and China Environmental Statistical Yearbook.

\subsection{Gross Domestic Product}

A strong link was found between environmental pollution and economic development. Local governments often lead to aggravation of environmental pollution while pursuing economic growth. Guangdong and Jiangsu provinces have the largest GDP in the country. These two provinces are both coastal provinces and have unique geographical advantages. One is in the Yangtze River Delta and the other is in the Pearl River Delta.

\subsection{GDP Per capita}

The Environmental Kuznets Curve have revealed that the emission or discharge of environmental pollutants is closely related to per capita income. Wastewater discharge goes up first and then down along with the growth of per capita GDP in China and show an inverted U-shaped trend in China, which means that the prediction model should include the logarithms of GDP per capita and its squared term. As shown in Figure 3b, GDP per capita is the highest in Shanghai and Tianjin.

\section{3. $R \& D$ investment}

It is an important indicator that reflects technological investment intensity, technological development level and technological innovation capability in a region. The greater the intensity of $R \& D$ investment is, the stronger the capacity for technological innovation become, and then the more the advanced technologies for pollution reduction will be obtained. Guangdong, Jiangsu, and Shandong province are among the top three in $R \& D$ investment.

\subsection{Foreign direct investment}

Foreign direct investment is usually used in more advanced technologies and equipment, which helps to reduce energy consumption and pollution emissions, thereby achieving green or cleaner production. But in accordance with the pollution haven hypothesis, FDI may worsen environmental quality by moving polluting industries from abroad to China. The amounts of foreign direct investment in Guangdong and Jiangsu are the best two in the country.

\subsection{Industrial structure}

The acceleration of the process of industrialization is often accompanied by the excessive exploitation of resources and environmental deterioration. With the development of society and economy, the decline in the proportion of the secondary industry in the national economy will ease the production of pollutants. Fujian, Jiangxi, Anhui, Henan, and Shaanxi provinces accounted for a larger proportion of the output value of the secondary industry.

\subsection{Environmental awareness}

Industrial pollution is the main influencing factor of environmental quality. The greater the investment in the treatment of industrial pollution is, the stronger the awareness of environmental protection is. Shandong Province has the strongest environmental awareness, and its industrial pollution control investment is the largest in China.

\section{CONCLUSION}

From the time series diagram of the total amount of wastewater discharge in China, we can see that the amount of wastewater discharge in the eastern and southern regions of China is higher, and that in the western and northern regions is lower. Guangdong Province and Jiangsu Province are the largest amount of wastewater discharge in China. The wastewater discharge of Qinghai Province, Gansu Province and Ningxia Hui Autonomous Region are at a low level. This paper selects six socio-economic factors that affect wastewater discharge, namely GDP, GDP per capita, foreign direct investment, industrial structure, R\&D investment and environmental awareness. Through the analysis, it is found that the GDP and foreign direct investment of Guangdong Province and Jiangsu Province rank the first in the country. Shanghai and Tianjin have the highest per capita GDP. Guangdong Province, Jiangsu Province and Shandong Province are the top three in R\&D investment. Fujian, Jiangxi, Anhui, Henan and Shaanxi provinces account for a large proportion of the secondary industry, and Shandong Province has the strongest awareness of environmental protection. The greater the GDP, the higher the per capita income, the heavier the environmental pollution and the more wastewater discharge. The lower the proportion of the secondary industry will reduce the production of wastewater. The stronger the awareness of environmental protection and the greater the R \& D investment, the less wastewater discharge. Foreign direct investment usually has two sides, it may not only realize cleaner production by introducing more advanced technology and equipment, 
but also transfer the polluting industry from abroad to China and thus aggravate the deterioration of the environment.

\section{AUTHORS' CONTRIBUTIONS}

Conceptualization, Fang Wang; Investigation, Fang Wang; Methodology, Fang Wang; Supervision, Hsing Hung Chen; Validation, Hsing Hung Chen and Fang Wang; Writing - original draft, Fang Wang; Writing review \& editing, Hsing Hung Chen. All authors have read and agreed to the published version of the manuscript.

\section{REFERENCES}

[1] D. P. Hader, A. T. Banaszak, V. E. Villafane, et al. Anthropogenic pollution of aquatic ecosystems: Emerging problems with global implications. Science of the Total Environment, 2020, 713: 136586 . DOI: https://doi.org/10.1016/j.scitotenv.2020.136586

[2] R. P. Schwarzenbach, T. Egli, T. B. Hofstetter, et al. Global water pollution and human health. Annual Review of Environment and Resources, 2010, 35(1): 109-136. DOI: https://doi.org/10.1146/annurev-environ-100809$\underline{125342}$

[3] S. A. Ostroumov. Water Quality and Conditioning in Natural Ecosystems: Biomachinery Theory of Self-Purification of Water. Russian Journal of General Chemistry, 2018, 87(13): 3199-3204. DOI: https://doi.org/10.1134/s107036321713014x

[4] F. Seker, H. M. Ertugrul, M. Cetin. The impact of foreign direct investment on environmental quality: A bounds testing and causality analysis for Turkey. Renew. Sust. Energ. Rev., 2015, 52: 347-356. DOI: https://doi.org/10.1016/j.rser.2015.07.118

[5] B. $\mathrm{Xu}, \mathrm{B}$. Lin. What cause large regional differences in $\mathrm{PM}_{2.5}$ pollutions in China? Evidence from quantile regression model. J. Clean Prod., 2018, 174: 447-461. DOI: https://doi.org/10.1016/j.jclepro.2017.11.008

[6] H. Liu, C. Fang, X. Zhang, et al. The effect of natural and anthropogenic factors on haze pollution in Chinese cities: A spatial econometrics approach. J. Clean Prod., 2017, 165: 323-333. DOI: https://doi.org/10.1016/j.jclepro.2017.07.127

[7] S. J. Wang, X. P. Liu, C. S. Zhou, et al. Examining the impacts of socioeconomic factors, urban form, and transportation networks on $\mathrm{CO}_{2}$ emissions in China's megacities. Appl. Energy,
2017, 185: 189-200. DOI: https://doi.org/10.1016/j.apenergy.2016.10.052

[8] M. A. Cole, R. J. R. Elliott, T. Okubo, et al. The carbon dioxide emissions of firms: A spatial analysis. J. Environ. Econ. Manage., 2013, 65(2): 290-309.

DOI: https://doi.org/10.1016/j.jeem.2012.07.002 